\title{
Cidades inteligentes como proposta de desenvolvimento local: uma análise conceitual para a cidade de Campina Grande/PB
}

Uma alternativa em destaque nos dias atuais em relação a sustentabilidade e o uso adequado do espaço urbano, é o modelo de Cidades Inteligentes - SmartCities. Estas visam o uso racional dos recursos naturais utilizando, da melhor forma possivel, as inovações tecnológicas. Dessa forma, esse estudo objetiva analisar conceitualmente o crescimento e desenvolvimento urbano, abordando o planejamento urbano e a organização espacial, assim como, a proposta de inserção de Smart City, na Cidade de Campina Grande, PB. O método utilizado no estudo, baseia-se em pesquisas bibliográficas, de autores conceituados, como também, respalda-se em informações coletadas em meios midiáticos (jornais e sites locais). Destaca-se que Campina Grande é um dos espaços urbanos que sedia um protótipo da Cidade Inteligente, tendo sido escolhida por deter potencial no âmbito tecnológico e na economia regional. Contudo, para se alcançar os pilares do desenvolvimento sustentável local e para se ter êxito na aplicação da Smart City, é necessário a obtenção de uma Gestão urbana eficaz, englobando diversos aspectos de conjuntura política, social, econômica e ambiental.

Palavras-chave: Cidades inteligentes; Urbanização; Sustentabilidade.

\section{Cathracha cliste mar thogra d'fhorbairt áitiúil: anailís choincheapúil do chathair Campina Grande/PB}

An alternative currently highlighted in relation to sustainability and the adequate use of urban space is the Intelligent Cities model - SmartCities. These aim at the rational use of natural resources using, as best as possible, technological innovations. Thus, this study aims to conceptually analyze urban growth and development addressing urban planning and spatial organization, as well as the proposal to insert Smart City, in the City of Campina Grande, PB. The method used in the study is based on bibliographical research, from well-known authors, as well as from information collected in media (newspapers and local sites). It is noteworthy that Campina Grande is one of the urban spaces that houses a prototype of the Intelligent City, having been chosen because it holds potential in the technological sphere and in the regional economy. However, in order to achieve the pillars of local sustainable development and to succeed in the implementation of Smart City, it is necessary to achieve an effective urban management, encompassing diverse aspects of political, social, economic and environmental conjuncture.

Keywords: Intelligent cities; Urbanization; Sustainability.

Topic: Gestão Pública

Reviewed anonymously in the process of blind peer
Received: 04/04/2021

Approved: 06/06/2021
Antonio Fagundes Gomes da Silva (iD

Universidade Federal de Campina Grande, Brasi

http://lattes.cnpq.br/9633805165150240

http://orcid.org/0000-0003-4025-2045

fagundes-gomes@hotmail.com

Ane Caroline Rodrigues Leite

Universidade Federal do Cariri, Brasil

http://lattes.cnpq.br/2649115904289783

http://orcid.org/0000-0002-7298-9810

carol.ane@live.com.br

Helena Maria da Conceição de Araújo (ib

Universidade Federal de Campina Grande, Brasil

http://lattes.cnpq.br/2886999498146511

http://orcid.org/0000-0001-6643-6817

helenaaraujo.geo@gmail.com

\author{
Renato de Bozzano Rodrigues \\ Universidade Federal do Pernambuco, Brasi \\ http://lattes.cnpq.br/242502051302171 \\ http://orcid.org/0000-0003-1913-5143 \\ renato_fip@hotmail.com \\ Thayse Machado Rodrigues (i) \\ Faculdades integradas de Patos, Brasil \\ http://orcid.org/0000-0002-7334-255X \\ thaysefmachado@gmail.com \\ Raiff dos Santos Silva \\ Faculdade Estácio de João Pessoa, Brasil \\ http://lattes.cnpq.br/3141388403876772 \\ http://orcid.org/0000-0002-5624-1538 \\ raiff@gmail.com
}

Referencing this:

SILVA, A. F. G.; LEITE, A. C. R.; ARAÚJO, H. M. C.; RODRIGUES, R. B.; RODRIGUES, T. M.; SILVA, R. S.. Cidades inteligentes como proposta de desenvolvimento local: uma análise conceitual para a cidade de Campina Grande/PB. Revista Brasileira de Administração Científica, v.12, n.2, p.246-256, 2021. DOI: http://doi.org/10.6008/CBPC2179$684 X .2021 .002 .0020$ 


\section{INTRODUÇÃO}

A conexão existente entre a urbanização e desenvolvimento, e as implicações dessa relação para a pobreza e o meio ambiente tem se tornado uma grande preocupação nos tempos hodiernos, considerando que cresce exponencialmente a concentração populacional nas cidades, principalmente, de baixa e média renda (TUROK et al., 2013). Embora esse cenário mostre-se tão real e presente quanto parece, é possível se enxergar soluções potenciais na promoção, por exemplo, de gestão eficiente, inovadora e mais inclusiva, ou seja, que proporcione o desenvolvimento local sustentável.

Nesse sentido, as modernas tecnologias podem apresentar-se como ferramentas cruciais de gestão das cidades para controlar os processos em prol da melhoria, inclusive, na qualidade de vida dos cidadãos em meio às transformações na evolução populacional e no espaço urbano. Todavia, não é dada a atenção suficiente à dinâmica da urbanização e à natureza do crescimento, haja vista que as condições necessárias para que isso ocorra também são negligenciadas, juntamente com as consequências do crescimento para as comunidades pobres e o esgotamento dos recursos naturais (TUROK et al., 2013).

Observa-se uma crise distopia onde os recursos naturais diminuem em função do uso intensivo e racional sendo desproporcional, pois, a capacidade de recuperação do meio ambiente, tendo em vista essa pressão da superpopulação e as mudanças climáticas. Assim, emerge-se uma luta desesperada pelo acesso aos recursos naturais, inclusive os escassos, desencadeada pela ação antrópica de forma predatória. Vive-se, então, momentos incertos. E não apenas ao acesso em si a estes recursos, mas uma corrida exaustiva em busca de modelos que atendam as premissas da sustentabilidade.

Para a melhor disseminação da sustentabilidade no espaço urbano, observou-se, então, que o modelo de Cidades Inteligentes - Smart Cities - aponta-se, nos dias atuais, como uma alternativa louvável, por meio de uma infraestrutura tecnológica flexível e construída localmente para criar conexões confiáveis e prontas adequadas a contextos diferentes. Estas visam o uso racional dos recursos naturais utilizando e priorizando, da melhor forma possível, as inovações tecnológicas.

As cidades inteligentes dependem não apenas de estruturas digitais, mas do "desenvolvimento contínuo da capacidade de aprendizagem para a inovação e replicação nos processos de gestão da dinâmica urbana" (WEISS et al., 2014).

Desenvolve-se, pois, ferramentas e tecnologias de cidades inteligentes a um ritmo crescente. As organizações de planejamento e as cidades ainda são desafiadas a encontrar formas efetivas de usar as ferramentas para atender o interesse público e responder às necessidades dos cidadãos.

Desse modo, este estudo objetiva analisar conceitualmente o crescimento e desenvolvimento urbano, abordando o planejamento urbano e a organização espacial, assim como, a proposta de inserção de Smart City, na Cidade de Campina Grande, PB. O método utilizado no estudo, emerge de pesquisas bibliográficas, respalda-se em informações coletadas em meios midiáticos (jornais e sites locais) sobre Campina Grande ser projetada um espaço urbano do protótipo da Cidade Inteligente, escolhida por ser caracterizada pelo potencial tecnológico e economia regional. Contudo, para se alcançar os pilares do 
desenvolvimento sustentável local e para se ter êxito na aplicação da Smart City, é necessário a obtenção de uma Gestão urbana eficaz, englobando diversos aspectos de conjuntura política, social, econômica e ambiental.

Tendo em vista que propostas como está tendem a desempenhar um papel integral na forma como planeja-se, construir-se e atende-se as demandas de cunho social, econômico e ambiental. Destarte, 'o conceito de cidade inteligente surge como uma nova dimensão da gestão pública para o enfrentamento desses desafios'.

\section{METODOLOGIA}

\section{Crescimento, desenvolvimento e urbanização}

Para olhar o urbano, aquele que salta dos olhos por meio da janela lateral, que ininterruptamente, intenso e intencionalmente refaz todo o contexto envolto, quer seja modificado ou ainda em fase de modificação, é imprescindível assentar-se sobre os questionamentos, aquele, por exemplo, que repousou o renomado Harvey (2001), quando no prefácio de sua obra Produção Capitalista do Espaço fala que cogitou em sua mente que "não havia conflito real entre a abordagem científica racional em relação às questões geográficas e aplicação eficiente do planejamento nas questões políticas". As indagações sobre o real modo de produção no espaço foram fundamentais para que se alcançasse uma compreensão mais madura acerca do tema.

A forma como o debate foi regido em torno da compreensão do espaço não deixa dúvidas para perceber que a aceleração do tempo e as transformações urbanas resultantes, foram tão intensas que tornou a cidade obsoleta sem que está sequer tenha envelhecido, o que é a expressão de um processo em rápido movimento a duras metamorfoses e autofagia (CARLOS, 2007).

Por meio da moção primeira de Harvey (2001) sobre a abordagem das relações geográficas face às políticas públicas de planejamento espacial, se torna fundamental enfatizar que é tênue a linha que separa os interesses privados dos interesses coletivos sobre o espaço, sendo indissociável pensar em ocupação e organização territorial, sem antes pensar nos interesses individuais da classe capitalista e dos grandes intelectuais de época afinados com a temática; que sobrepujam lançar pilares para a compreensão de uma nova concepção do processo real de produção do espaço ${ }^{1}$.

Seguindo a proposta de análise de Breda (2005), é importante compreender primeiro os

[...] aspectos conceituais mais abstratos relativos à produção social do espaço para depois avançar na perspectiva de produção do espaço capitalista, desde o espaço da produção (a construção) como primeiro momento, passando pelo espaço como produto (mercadoria) e como instrumento, até a produção do espaço abstrato - espaço capitalista por excelência e suas contradições com a própria forma urbana que ele representa.

Morais et al. (2014) considera que "a vida tem o mesmo valor em qualquer espaço e tempo". Mas, o capital, assim como a vida, está ajustado nesta mesma configuração em relação ao espaço e tempo? Para a idealização e acomodação do capital foi preciso contar com a ajuda de um complexo processo de urbanização

${ }^{1}$ Ver Carlos (2005) em O Espaço da Produção e a Produção do Espaço. 
generalizada, que envolvesse as relações sociais, concretamente, dentro das relações espaciais. Ou seja, é dentro do espaço que o produto social realizado pelos diversos agentes, ganha forma e valor. Não há outro lugar, se não dentro do próprio espaço, que as atividades humanas são realizadas e, consequentemente, valoradas- a não ser dentro da calculista imaginação do capital(ista). Condição sinequa non é possível "[...] conceber o espaço como produto da ação humana, aspecto da 'segunda natureza' humana" (BREDA, 2005).

Dessa maneira, a rede urbana pode ser entendida como um conjunto de centros funcionalmente articulados que se constituem num reflexo social, resultado de complexos e mutáveis processos engendrados por diversos agentes sociais. Assim, parte-se do pressuposto de que a urbanização reflete e condiciona ao mesmo tempo a estrutura e o processo de mudanças, contidos nas relações sociais e nas formas de produção, para conformação específica de uma totalidade social (MORAIS et al., 2014).

Já Lefebvre (1999), em referência ao urbano, definiu-o não como uma realidade acabada, mas que, situado na realidade atual, se coloca como horizonte, como virtualidade iluminadora, que vai sendo aos poucos desenhada, continuadamente. Isto porque "a capacidade de dotá-lo de alguma utilidade social, de convertê-los em valores de uso, depende do ser humano, mais especificamente do trabalho humano" (BREDA, 2005, citado por MARX, 1982).

Nessa concepção, o "urbano" vai sendo aos poucos construído/edificado. E "[...] considerando o desprezo pela existência dos povos, pelo conteúdo da vida, pela destruição da natureza e do ser[...] (MORAIS et al., 2017)", demonstra-se que não está na zona de interesse na relação capital-urbano, contemplar as particularidades de cada comunidade- a considerar as diferentes culturas, costumes e especificidades inerente de cada espaço no globo- se não o afã do capital como moderador de uma espacialidade regida sob os auspícios de uma ideia reduzida baseada em espaço do consumo e da reprodução da força de trabalho.

A terminologia "urbano" pode estar referida ao que é relativo ou pertencente à cidade, logo, a urbanização é o conjunto articulado entre as espacialidades (cidades, vilas) que possibilita com que essa articulação na estrutura social se dê na forma de uma integração econômica, capaz de imprimir na estrutura social um ordenamento hierarquicamente organizado entre esses espaços (LEFEBVRE, 1999), o que automaticamente trauteia uma espécie de indiferença e desprezo tanto pelas condições de vida, como pelas culturas locais construídas ao longo do tempo no espaço.

\begin{abstract}
Como resultado surgem novos padrões e formas de adaptação decorrentes da imposição de um novo modo de apropriação do espaço da cidade. Assim nos deparamos com formas cada vez mais mutantes em um tempo cada vez mais efêmero, produto de uma nova racionalidade imposta por profundas mudanças no processo de acumulação. Assim, uma nova relação espaço-tempo domina o mundo, onde a efemeridade do tempo no espaço revela a produção de um 'espaço amnésico'. Essa relação entre 'tempo efêmero' e 'espaço amnésico' é fundamental para definir a pós-modernidade. (BREDA, 2005, citado por LEFEBVRE, 2006).
\end{abstract}

Recapitulando as suposições do parágrafo passado, faz-se necessário se desprender da ultrapassada ideia sustentada por alguns, de que o urbano se apresenta meramente como unidade espacial que existe unicamente com o propósito de contribuir para a reprodução da força de trabalho e seus derivados. Afastase desta concepção, o processo de produção do espaço como forma continuada, edificada pelos constructos artificiais humanos de interesse, içados para ele e por meio dele, o capital. 
Essa problemática, faz parte de um conjunto de barreiras há serem vencidas na perspectiva de caminhar para um desenvolvimento local sustentável (DLS), fortalecendo as capacidades dos poderes públicos municipais e das organizações da sociedade civil visando a implementação de ações, políticas públicas, programas e projetos de apoio ao desenvolvimento.

No entanto, a controvérsia entre os conceitos de crescimento econômico e desenvolvimento ainda não foi bem esclarecida.

Poucos são os outros conceitos nas Ciências Sociais que se têm prestado a tanta controvérsia. Conceitos como progresso, crescimento, industrialização, transformação, modernização, têm sido usados frequentemente como sinônimos de desenvolvimento. Em verdade, eles carregam dentro de si toda uma compreensão específica dos fenômenos e constituem verdadeiros diagnósticos da realidade, pois o conceito prejulga, indicando em que se deverá atuar para alcançar o desenvolvimento.

Souza (1993) aponta a existência de duas correntes de pensamento econômico sobre o tema. A primeira corrente encara o crescimento como sinônimo de desenvolvimento, enquanto na segunda, crescimento é condição indispensável para o desenvolvimento, mas não é condição suficiente. Na primeira corrente estão os modelos de crescimento da tradição clássica e neoclássica, Já na segunda corrente estão os economistas de orientação crítica, formados na tradição marxista ${ }^{2}$ ou cepalina ${ }^{3}$, que conceitua o crescimento como uma simples variação quantitativa do produto, enquanto desenvolvimento é caracterizado por mudanças qualitativas no modo de vida das pessoas, nas instituições e nas estruturas produtivas.

É, nestes ventos de mudança estruturais, políticas e conceituais que a ONU4 já em 1945 inicial debates referentes às desenvolvimento. Doravante destaca Oliveira (2002):

Desde sua criação, a ONU está empenhada em: promover o crescimento e melhorar a qualidade de vida dentro de uma liberdade maior; utilizar as instituições internacionais para promoção do avanço econômico e social; conseguir cooperação internacional necessária para resolver os problemas internacionais de ordem econômica, social, cultural ou de caráter humanitário; e promover e estimular o respeito aos direitos humanos e as liberdades fundamentais de toda a população do globo, sem distinção de raça, credo, sexo, idioma ou cor. Agindo globalmente ou localmente.

Os poderes públicos devem desempenhar um importante papel no desenvolvimento socioeconômico. A constituição de um arranjo político-institucional, articulando o conjunto dos atores do território, visando a promoção do desenvolvimento sustentável, somente se viabiliza quando os poderes públicos - particularmente o poder público local - assumem suas responsabilidades nessa matéria.

Nesta perspectiva, compreende-se o conjunto de ideias até aqui apresentadas como necessárias na construção de um projeto de desenvolvimento local, considerando ainda a expansão progressiva, desestruturada e desigual da cidade como consequência do mal planejamento urbano. Problemática essa que deve ser superada perante os princípios básicos da sustentabilidade, que entre outros, prega a busca por um ambiente socialmente justo, economicamente viável e ambientalmente correto.

\footnotetext{
2 Pensamento formado no modelo criado por Karl Marx que defende a supressão da exploração do homem por seu semelhante e a instalação do regime socialista.

${ }^{3}$ Refere-se aos economistas que seguem os ensinamentos da CEPAL - Comissão Econômica para América Latina e Caribe.

${ }^{4} \mathrm{~A}$ Organização das Nações Unidas, também conhecida pela sigla ONU, é uma organização internacional formada por países que se reuniram voluntariamente para trabalhar pela paz e o desenvolvimento mundiais.
} 


\section{DISCUSSÃO TEÓRICA}

\section{Organização espacial e planejamento urbano}

Analisando o processo de produção social do espaço urbano ao longo da história, nota-se que este adquire valor, quando "[...] ele se vende, se compra; ele tem valor de troca e valor de uso" (LEFEBVRE, 2006). O espaço de indústrias, comércio, política, estratégia etc., ou seja, o que produz bens de consumo direto e indireto, metamorfoseando-se também em mercadoria - já que emerge valor de troca e uso pelo capital -e implica nas dinâmicas sociais cotidianas e no espaço vivido. 0 espaço- mercadoria circula em diferentes velocidades de tempo e localidades, torna-se propriedade de atores hegemônicos, quantificação de produção e pedaço comercializado de forma fragmentada a reprodução da vida cotidiana.

Assim, o espaço urbano: fragmentado e articulado, reflexo e condicionante social, um conjunto de símbolos e campo de lutas. É assim a própria sociedade numa de suas dimensões, aquela mais aparente, materializada nas formas espaciais (CORRÊA, 1989). A cidade como espaço materializado, que simultaneamente representa a forma do processo de (re)produção de um sistema específico, no caso o capitalista, portanto, a cidade é a apropriação do espaço urbano produzido, sendo

Um produto concreto, a cidade, o campo, o território - nessa perspectiva o espaço, enquanto dimensão real que cabe intuir - colocam-se como elementos visíveis, representação de relações sociais reais que a sociedade é capaz de criar em cada momento do seu processo de desenvolvimento. Consequentemente, essa forma apresenta-se como história, especificamente determinada, logo concreta. (CARLOS, 2007)

As camadas sociais que interagem com o espaço urbano exercem forte influência na expansão das cidades, Correa afirma que:

A grande cidade capitalista é o lugar privilegiado de ocorrência de uma série de processos sociais, entre os quais há acumulação de capital e a reprodução social tem importância básica. Estes processos criam funções e formas espaciais, ou seja, criam atividades e suas materializações, cuja distribuição espacial constitui a própria organização espacial urbana (CORRÊA, 1989).

O sistema irá ditar as regras para o crescimento urbano, e o processo é realizado de acordo com as condições econômico- políticos- sociais que atendam as demandas de habitação, de produção, de serviços etc. No processo de formação do espaço há uma inerente dimensão política que leva a diferentes formas de controle sobre o espaço (CASTRO et al., 2014). A organização espacial depende consideravelmente da atenção às necessidades do Homem:

No processo de organização de seu espaço o Homem age seletivamente. Decide sobre determinado lugar segundo este apresente atributos julgados de interesse de acordo com os diversos projetos estabelecidos. A fertilidade do solo, um sítio defensivo, a proximidade da matéria-prima, o acesso ao mercado consumidor ou a presença de um porto, de uma força de trabalho não qualificada e sindicalmente pouco ativa, são alguns dos atributos que podem levar a localizações seletivas. (CASTRO et al., 2014)

Ou seja, produção do espaço ocorre de acordo com as necessidades da população atendendo a determinados interesses, podendo ser privados, públicos e coletivos.

O solo urbano configura-se como um elemento atrativo de interesse dos agentes sociais - (i)legais, isolados, articulados, com elevado poder aquisitivo ou mediano - que pode investir mesmo antes do alvo do investimento não apreende valorização no momento. Com isso, a produção do espaço adquire-se a partir de 
um conteúdo sócio político, partindo da perspectiva que o espaço é moldado pelos diversos grupos que compõem a sociedade expondo os interesses múltiplo. O espaço (re)produzido torna-se, assim, um campo reprodução de lutas sociais, conflitos econômicos e instrumento de poder e controle.

Corrêa (2003) discute a respeito das dificuldades da organização especial, destacando que a maior seria estudar a sociedade e suas necessidades, sobretudo a complexidade e diversidade, que interagem na totalidade social. A organização espacial é formada por um conjunto de objetos fixos ou formas espaciais distribuídas ou organizadas sobre a superfície da Terra de acordo com alguma lógica. Por conseguinte, ela pode ser entendida como a segunda natureza, a natureza primitiva que foi transformada pelo trabalho social (CORRÊA, 2003). Penar na organização do espaço como produto social, prevê que este espaço deve suprir a necessidades humanas, sem degradar o meio, tornando a homem parte da natureza e utilizando de seus recursos racionalmente e de maneira inteligente e sustentável.

\section{Cidades inteligentes como alternativa para o desenvolvimento local sustentável: o caso de Campina Grande/PB}

O modelo de cidades inteligentes emerge no sentido do planejamento e gestão eficiente do espaço urbano atendendo a demanda das necessidades da sociedade contemporânea, inserido na busca pela sustentabilidade, o modo de agir local sob essa nova perspectiva está a cada dia mais indispensável para atingir o desenvolvimento local; paralelo a essa busca, existe também, um processo de descentralização social, econômica e política. Para Rodrigues et al. (2010), "sustentabilidade vai muito além de um movimento de ecologistas e ambientalista, e sim uma atitude administrativa que pode resultar em ganho financeiro para as empresas". No desenvolvimento sustentável que nada mais é que uma nova gestão de empresas e negócios que não tolera desperdício e degradação do solo, água e ar atmosférico, tem-se como resultado uma economia limpa que traz benefícios não só para quem produz desta maneira, mas a todos que indiretamente participam e se beneficiam deste meio de produção.

Nesta nova economia, ou como trata Leff (2010) "uma 'outra economia', que procura flexibilizar, limitar, regulamentar e controlar excessos da racionalidade econômica [...] sobre bases ecológicas e culturais". Percebe-se a necessidade do desenvolvimento econômico partindo de atividades sustentáveis, contudo, o desenvolvimento sustentável vem atrelado a outros conceitos e práticas, como: desenvolvimento humano e social, capital social, consumo sustentável, responsabilidade ambiental, consumidor ecologicamente consciente e educação ambiental (KEINERT, 2006).

Com isso, a mudança da racionalidade econômica para uma racionalidade ambiental e adoção de práticas de economia sustentável e limpa só é possível haja vista uma efetiva e formulada sensibilização coletiva pela educação ambiental, definida como processo que busca desenvolver uma população consciente e preocupada com o meio ambiente [...], um processo dinâmico, permanente e participativo, onde as pessoas envolvidas passem a ser agentes transformadores (SOUZA et al., 2011). Para tanto, 'o tipo de desenvolvimento desejável propõe uma conciliação entre o desenvolvimento e o crescimento econômico, sendo, simultaneamente, sensível à dimensão social, ambientalmente prudente e economicamente viável’. 
O desenvolvimento local pode ser conceituado como um processo endógeno de mudança, que leva ao dinamismo econômico e à melhoria da qualidade de vida da população em pequenas unidades territoriais e agrupamentos humanos. Para ser consistente e sustentável, o desenvolvimento local deve mobilizar e explorar as potencialidades locais e contribuir para elevar as oportunidades sociais e a viabilidade e competitividade da economia local; ao mesmo tempo, deve assegurar a conservação dos recursos naturais locais, que são a base mesma das suas potencialidades e condição para a qualidade de vida da população local (BUARQUE, 2008).

O desenvolvimento local é uma busca que transcende a esfera econômica, por que demanda mudanças institucionais que aumentam a governabilidade e a governança das instituições públicas locais, incluindo o município, construindo uma relativa autonomia das finanças públicas e acumulação de excedentes para investimentos sociais e estratégicos para a localidade (BUARQUE, 2008). Pode ser entendido como um processo endógeno, por que o crescimento econômico vislumbrado está em consonância com a capacidade de absorção da localidade no que se refere exploração dos recursos naturais e a potencialização da capacidade produtiva.

Esse desenvolvimento resulta a interação e a sinergia entre a qualidade de vida da população local, a redução da pobreza, a geração de riqueza e a distribuição de ativos; a eficiência econômica (possibilitada pela agregação de valor na cadeia produtiva) e a gestão pública eficiente. A interação entre esses fatores sendo mediadas: pela governança, transbordando da base econômica para as finanças e os investimentos públicos - pela organização da sociedade - orientando as políticas e os investimentos públicos locais - e pela distribuição de ativos sociais, assegurando a internalização da riqueza e os desdobramentos sociais da economia. Portanto esses são os três grandes pilares do desenvolvimento sustentável local (a qualidade de vida, a eficiência econômica e a gestão pública eficiente) formando uma combinação de fatores que pode promover a reorganização da economia e da sociedade locais, além da conservação ambiental (BUARQUE, 2008).

Para a melhor aplicação da sustentabilidade no espaço urbano a alternativa melhor difundida é o modelo de cidades inteligentes, que parte do preceito orientar o uso racional dos recursos visto que a economia de energia - 2/3 do consume mundial de energia advém das cidades -, manejo de resíduos sólidos - 75\% são gerados nas cidades-, esgotamento de recursos hídricos e consumo exacerbado de água potável etc. (LEITE, 2012). Esse modelo de cidade inteligente tem por base as inovações tecnológicas, Leite (2012) afirma que: "as cidades inteligentes, smartcities, podem e devem alavancar a otimização da vida urbana, seja com serviços avançados na cidade formal, seja nas novas oportunidades nos territórios informais", ou seja, mesmo que serviços complexos e que requerem grande investimento, pode haver um planejamento com inovações mais acessíveis, práticos para lugares mais densos e com poder aquisitivo menor.

Um dos mecanismos de desenvolvimento das smartcities (a cidades pequenas, compactas, leves, econômicas, de matriz energética limpa e ciclo de vida contínuo, carros compartilhados, qualidade no transporte público, área verdes e seguras à população) é a ideia de crescer para dentro das metrópoles e não mais expandir - como ideologia difundida em países em desenvolvimento -, reciclando territórios. "As 
cidades se reinventam. Afinal elas não foram fossilizadas: as melhores cidades, aquelas que continuamente sabem se renovar, funcionam similarmente a um organismo - quando adoecem, se curam, mudam" (LEITE, 2012). O modernismo, a boa arquitetura e projetos de conforto ambiental urbano são mecanismos de suma importância para o crescimento das cidades inteligentes.

Ultimamente, o que tem sido um dos temas centrais de discussão econômica é a aplicação dos clusters - são aglomerações industriais geograficamente localizadas e interligadas que aumentam a produção, concentração e eficiência, através de inovações tecnológicas; estes são uma forma eficiente para o desenvolvimento local, proporcionando relação de cooperação entre as empresas e maior alcance dos serviços pela sociedade. Partindo da perspectiva que um dos primeiros passos para a montagem de clusters é a identificação de potencial regional/local existente, políticas públicas e iniciativa privada e instalação de grandes complexos industriais, que gera a promoção do desenvolvimento industrial e social local $\left.\right|^{5}$.

Analisando em âmbito local, a Região Metropolitana de Campina Grande, localizada no estado da Paraíba, criada pela Lei Complementar Estadual no 92/2009, atende, a partir do projeto pelo Sebrae intitulado SmartCities em Campina Grande, o modelo de implantação de mecanismos que possibilitem um desenvolvimento local sustentável e racional. Através de plataformas digitais, aplicativos e ferramentas de mobilidade urbana, saúde, educação etc.

A cidade de Campina Grande, no agreste paraibano, se prepara para se tornar uma Cidade Inteligente. Na última terça-feira (9), durante o 1 o Workshop de Startups:Cidadelnteligente e modelos de gestão eficiente, promovido pela Prefeitura de Campina Grande na Federação das Indústrias do Estado da Paraíba (FIEP), o Sebrae apresentou o projeto piloto de SmartCities do Sebrae Nacional, que selecionou Campina Grande e outras cinco cidades brasileiras para integrar a iniciativa ${ }^{6}$.

O presidente do Sebrae - João Alberto Miranda -, no lançamento do projeto, afirma que Campina Grande detém de um grande potencial para destacar-se na economia regional, visto a expressiva demanda de empresas que crescem em número e oportunidades no município. Atualmente na cidade é observado os serviços que vêm a melhorar a qualidade de vida das pessoas, permitindo o controle do cliente e otimização dos recursos das empresas, exemplo disso, são os serviços de comércio denominados foodstruks, em pontos estratégicos, aplicativos de fastfood atualizando-se aos poucos, também os de mobilidade urbana e segura e redes de cooperação e compartilhamento. Para isso, instituições estão contribuindo de forma positiva com as inovações tecnológicas,

Sobre a fibra ótica e suas transformações sociais, uso da população e desenvolvimento das novas tecnologias, o professor Reinaldo Gomes, da Universidade Federal de Campina Grande (UFCG) disse que as instituições tecnológicas logo mostrarão os resultados. "Esse projeto de Cidades Inteligentes pretende instalar a comunicação que faltava entre os setores e interligá-los. Com ele em pleno funcionamento, com o Sebrae e demais instituições de apoio, será possível saber de fluxos de veículos e pessoas e até sobre atendimentos na saúde", falou. Mais quatro palestrantes apresentaram os temas gestão eficiente e cidadania digital, inovação tecnológica na gestão pública de saúde, produção de semáforos e aplicativos. O proprietário da startup Mavip, Vinícius Travassos, foi o primeiro a falar sobre marcas. Outros quatro empresários do mesmo segmento, da IsNotTrash, da Conhecer Iniciativa Educacional, da GSA Sol e City Guia, apresentaram seus serviços e produtos. O evento foi uma realização da secretaria de Ciência, Tecnologia e Inovação, com apoio das ACCG, Sebrae, FIEP e UFCG ${ }^{7}$.

\footnotetext{
${ }^{5}$ Disponível em http://www.jornaldaparaiba.com.br/vida urbana

${ }^{6}$ Disponível em /vida_urbana/

${ }^{7}$ Disponível em http://www.jornaldaparaiba.com.br/vida_urbana/
} 
Assim, o projeto de Cidades Inteligentes que chega a Campina Grande e está sendo elaborado e lançado no ano de 2017, durará 20 meses e contará com um investimento de $\mathrm{R} \$ \mathbf{5} 50$ mil para diversas empresas, objetivando o auxílio às empresas a se desenvolverem através da inovação tecnológica, planejamento e gestão com eficiência.

\section{CONCLUSÕES}

Através da compreensão acerca do espaço, percebeu-se que a rapidez do tempo e as transformações urbanas resultantes foram muito intensas, tornando as cidades atrasadas, sem mesmo terem envelhecido, resultado de um processo em constante movimento. Dentro do espaço, onde as atividades humanas são realizadas, a rede urbana é considerada como um conjunto de centros articulados que se constituem num reflexo social, decorrência de difíceis e inconstantes processos causados por diversos agentes sociais, que contribuem para a formação de uma integração econômica.

Sabe-se que os poderes públicos necessitam exercer um desempenho relevante no desenvolvimento socioeconômico. Nesta perspectiva, entende-se que para a construção de um projeto de desenvolvimento local, deve-se considerar o crescimento progressivo, desestruturado e desigual da cidade como consequência do mal planejamento urbano. Fator esse que deve ser superado perante os princípios básicos da sustentabilidade, que entre outros, foca na busca por um ambiente socialmente justo, economicamente viável e ambientalmente correto.

Para isso, é imprescindível considerar o planejamento urbano e a organização do espaço, sendo estes fatores influenciados pelas políticas públicas, governo, educação, estrutura da cidade, cultura, entre outros. Com isso, a produção do espaço adquire-se a partir de um conteúdo sócio-político, partindo da perspectiva que o espaço é moldado por diversos grupos que compõem a sociedade expondo aos interesses múltiplos. Para a obtenção de um recinto adequado, é essencial também considerar as inúmeras necessidades da população como: habitação, renda, emprego, demanda por serviços na área de saúde, educação, entretenimento.

Compreendeu-se que nas últimas décadas o enfoque no quesito ambiental vem aumentando cada vez mais, sendo este um critério que não se pode mais desconsiderar. Portanto, quando se trata de desenvolvimento, crescimento, mudanças sociais e afins, a variável ambiental ocupa posição de destaque e de inteira relevância a ser analisado e estimado.

Desse modo, no que se refere à transição da racionalidade do âmbito econômico para uma racionalidade voltada para o foco ambiental, com a adoção de práticas sustentáveis e conscientes, só é possível com uma efetiva e formulada sensibilização coletiva pela educação ambiental. Para isso, é preciso infraestrutura eficaz e investimento assertivo, partindo, principalmente, dos governos, das empresas privadas e da sociedade.

Os três grandes pilares do desenvolvimento sustentável local são: a qualidade de vida, a eficiência econômica e a gestão pública eficiente, que em conjunto podem promover a reorganização da economia e da sociedade locais, além da conservação ambiental. Assim sendo, para a melhor aplicação da 
sustentabilidade no espaço urbano, observou-se que a alternativa, em destaque nos dias atuais, é o modelo de cidades inteligentes -smartcities. Já que visa o uso racional dos recursos naturais. A cidade inteligente tem como pretensão utilizar as inovações tecnológicas e aplica-las.

Como foi visto no estudo, a cidade Campina Grande detém de um grande potencial para destacar-se na economia regional, visto a expressiva demanda de empresas que crescem em número e oportunidades no município. Além de ser uma cidade universitária, com evidência nacional, que possui cursos superiores, recebe estudantes e profissionais de vários locais do país, obtém também o arcabouço no ramo da inovação e tecnologia, e por isso está em processo para hospedar a proposta de Smart City.

Contudo, como já discutido na pesquisa, para a implantação de mudanças desse porte, é preciso uma infraestrutura desenvolvida e investimento alto, que envolve aspectos de conjunturas políticas, empresariais, sociais, ambientais e da comunidade como todo. Por fim, para estudos futuros, é interessante que haja pesquisas voltadas para a fase de inserção e o acompanhamento assíduo da execução do projeto na cidade Campina Grande e realizar comparações com demais centros urbanos que já adotaram o sistema.

\section{REFERÊNCIAS}

BREDA, F. M.. O espaço da Produção e a Produção do Espaço Urbano. In: ENANPUR - ESPAÇO, PLANEJAMENTO E INSURGÊNCIAS, 16. Anais. Belo Horizonte: Universidade de São Paulo, 2005.

\section{BUARQUE, S.. Construindo o desenvolvimento local} sustentável: Metodologia de planejamento. São Paulo: Garamond, 2008.

CARLOS, A. F. A.. O espaço urbano: novos escritos sobre a cidade. São Paulo: FFLCH, 2007.

CASTRO, I. E.; GOMES, P. C. C.; CORRÊA, R. L.. Geografia: Conceitos e temas. 16 ed. Rio de janeiro: Bertrand Brasil, 2014.

CORRÊA, R. L.. Globalização e reestruturação da rede urbana: uma nota sobre as pequenas cidades. Território, Rio de Janeiro, v.4, n.6, p.41-53, 1989.

CORRÊA, R. L.. Espaço urbano. São Paulo: Ática, 2003.

HARVEY, D.. A produção capitalista do espaço. São Paulo: Annablume, 2001.

KEINERT, T.. O que é sustentável e o que se entender por sustentabilidade?. In: WORKSHOPP DE RISCO E SUSTENTABILIDADE, 2. Anais. São Paulo: USP, 2006.

LEFEBVRE, H.. A Revolução Urbana. 3 ed. Editora UFMG, 1999.

LEFEBVRE, H.. A produção do espaço. 4 ed. Paris: Éditions Anthropos, 2006
LEFF, E.. Discursos Sustentáveis. São Paulo: Cortez, 2010.

LEITE, C.. Cidades Sustentáveis, Cidade Inteligentes: desenvolvimento sustentável num planeta urbano. Porto Alegre: Bookman, 2012.

MORAIS, J. M. L.; MACEDO, F. C.; LIMA JUNIOR, F. O'.. Ceará: economia, urbanização e metropolização. Crato: RDS, 2014.

OLIVEIRA, G. B.. Uma discussão sobre o conceito de desenvolvimento. Rev. FAE, Curitiba, v.5, n.2, p.37-48, 2002.

RODRIGUES, L. A.; MARIETTO, M. L.. Agronegócio: inovação e gestão rumo a sustentabilidade. Revista Cientifica Sapere, v.2, n.2, 2012.

SOUZA, N. J.. Desenvolvimento econômico. São Paulo: Atlas, 1993.

SOUZA, F. M. N.; FARIAS, G. G.. Educação ambiental: um novo desafio para as empresas. In: Agenda Ambiental: Questão Socioambiental. Campina Grande: EDUEPB, 2011 p.61-76.

TUROK, I.; MCGRANAHAN, G.. Urbanization and economic growth: the arguments and evidence for Africa and Asia. Environment \& Urbanization, v.25, n.2, p.465-482, 2013. DOI: http://doi.org/10.1177/0956247813490908

WEISS, M. C.; BERNARDES, R. C.; CONSONI, F. L.. Cidades inteligentes como nova prática para o gerenciamento dos serviços e infraestruturas urbanos: a experiência da cidade de Porto Alegre. Revista Brasileira de Gestão Urbana, v.7, n.3, 2014. DOI: http://doi.org/10.1590/21753369.007.003.AO01

A CBPC - Companhia Brasileira de Produção Científica (CNPJ: 11.221.422/0001-03) detém os direitos materiais desta publicação. Os direitos referem-se à publicação do trabalho em qualquer parte do mundo, incluindo os direitos às renovações, expansões e disseminações da contribuição, bem como outros direitos subsidiários. Todos os trabalhos publicados eletronicamente poderão posteriormente ser publicados em coletâneas impressas sob coordenação da Sustenere Publishing, da Companhia Brasileira de Produção Científica e seus parceiros autorizados. Os (as) autores (as) preservam os direitos autorais, mas não têm permissão para a publicação da contribuição em outro meio, impresso ou digital, em português ou em tradução. 